Journal of Social and Development Sciences

Vol. 1, No. 5, pp. 194-201, June 2011

\title{
College Academic Stress: Differences along Gender Lines
}

\author{
Glenn M. Calaguas \\ Institute of Arts and Sciences, Pampanga Agricultural College Magalang, Pampanga, Philippines \\ glenn_calaguas@yahoo.com
}

\begin{abstract}
This study examined the perception of academic stress among college students in a state college in the Philippines highlighting gender differences. In order to achieve the purpose of the study, an indigenous survey instrument was developed. A total of 1,210 college students chosen through systematic random sampling responded to the survey instrument. To determine gender differences among the respondents, independent samples t-test was used via SPSS version 15.0. Statistical analyses showed that male and female respondents differed significantly in their perceptions of subject, teacher, schedule, classroom, and expectation-related stressors but did not significantly differ in their perceptions of enrolment and admission, classmate, and financial- related stressors. Generally, no significant difference was found between male and female respondents in their perception of academic stressors, however using the mean scores as basis, female respondents scored higher compared to male respondents.
\end{abstract}

Keywords: Academic stress, College Students, Gender Differences, Perception, State College

\section{Introduction and Literature}

Stress can be considered as "any factor, acting internally or externally, which makes adaptation to environment difficult and which induces increased effort on the part of the individual to maintain a state of equilibrium between himself and herself and the external environment" (Humphrey, Yow, \& Bowden, 2000, p. 2-3). Additionally, "stress is a physical and mental response to everyday demands, particularly those associated with change" (Richlin-Klonsky \& Hoe, 2003, p. 3). In recent years, "stress has become an important topic in academic circle" (Agolla \& Ongori, 2009, p. 63) probably because of the fact that life in general is flooded by many stresses. Among college students, stress can be viewed as a positive or negative experience that affects their lives and performances (Jogaratnam \& Buchanan, 2004). This is so because "academic work is never without stressful activities" (Agolla \& Ongori, 2009, p. 69) and "college students are at a critical period where they will enter adulthood" (Cheng, 2009, p. 2). The experience of stress among college students is considered normal but "if stress is severe and/or prolonged, it can reduce academic performance; interfere with a student's ability to participate in and contribute to campus life; and increase the likelihood of substance abuse and other potentially damaging behaviors" (Richlin-Klonsky \& Hoe, 2003, p. 3).

One form of stress that is constantly being experienced by college students is stress in relation to academic concerns. "Academic stress is the product of a combination of academic-related demands that exceed the adaptive resources available to an individual" (Wilks, 2008, p. 107). Academic stress is a concern that must not be taken for granted because it adversely affects the overall adjustment of students (Hussain, Kumar, \& Husain, 2008) and several studies have already documented the effect of stress on students (e.g. Agolla \& Ongori, 2009; Hussain et al., 2008; Masih \& Gulrez, 2006; Shaikh et al., 2004; Sulaiman, Hassan, Sapian, \& Abdullah, 2009). In 2005, Kumar and Jejurkar "found that academic factors were responsible for higher level of stress" (p. 13) among undergraduate students.

Components of Academic Stress: Many factors contribute to the stress being experienced by students but specifically, the following are associated with academic stress based on literature: time management issues financial burdens, interactions with teachers, personal goals, social activities, adjustment to the campus environment, lack of support networks (Wilks, 2008), admission procedures, high standards of parents, curriculum being highly concept laden, inappropriate school timings, high student-teacher ratio, nonconducive physical environment of classrooms, the absence of healthy teacher-student interaction, irrational 
rules of discipline, physical punishment, excessive or unbalanced school-work, teaching methodology, indifferent attitudes of teachers, overemphasis on weaknesses rather than strengths (Masih \& Gulrez, 2006), expectations of students themselves, expectations of parents, and expectations of teachers (Ang \& Huan, 2006).

Additionally, the following were recognized to be associated to academic stress based on studies: academic workload, attending lectures (Agolla \& Ongori, 2009), examinations, school curriculum (Shah, Hasan, Malik, \& Sreeramareddy, 2010), inadequate learning materials (Agolla \& Ongori, 2009; Shah et al., 2010), performance in academic work, academic difficulties (Agolla \& Ongori, 2009; Johnson, 2009), overcrowded classrooms (Agolla \& Ongori, 2009), subject-related projects (Conner, Pope, \& Galloway, 2010), uncertainty in getting a job after graduation/ worrying about the future (Agolla \& Ongori, 2009; Shah et al., 2010), self-expectations (Misra \& Castillo, 2004), expectations of peers, expectations of friends (Agolla \& Ongori, 2009), expectations of family members/parents (Agolla \& Ongori, 2009; Shah et al., 2010), financial limitations (Johnson, 2009), and college admission procedures (Conner et al., 2010).

Stress along Gender Lines: Investigation of the experience and perception of stress along gender lines is a fascinating undertaking because findings of studies conducted regarding stress with references to gender are somewhat conflicting. Say for example, in a study conducted by Misra and Castillo in 2004, it was revealed "that men and women differ in their perceptions and reactions to stress" (p. 146) while Jogaratnam and Buchanan (2004) found differences between male and female students to be significant when it came to the time pressure dimension of stress. In relation, Sulaiman et al. (2009) found in their study that "female students have different stress compared to the male students. This may be because female students tend to be more emotional and sensitive toward what is happening in their surrounding" (p. 183). On the other hand, Watson (2002) found no significant difference in the perceived stress between male and female students when the researcher made a comparison of perceived stress levels and coping styles of junior and senior students in Nursing and Social Work programs.

This study examines academic stress among college students enrolled in a state college in the Philippines with reference to gender differences. Specifically, these objectives are followed:

- To determine the differences in the perception of academic stress between males and females with reference to enrolment and admission, subject, teacher, classmate, schedule, classroom, financial, and expectation-related stressors.

- To determine the difference in the perception of academic stress between males and females in general.

\section{Hypotheses of the Study}

- There are significant differences in the perception of academic stress between males and females with reference to enrolment and admission, subject, teacher, classmate, schedule, classroom, financial, and expectation-related stressors.

- 2. There is a significant difference in the perception of academic stress between males and females in general.

\section{Method}

Development of the Survey Instrument: There was a need to develop an indigenous instrument because of the perceived need to truly capture the concerns of college students enrolled in a state college in the Philippines. The development of the instrument started with a review of extant literature regarding academic stress and a focus-group interview among 20 college students (18 Doctor of Veterinary Medicine and two Hotel and Restaurant Management) aimed to identify their academic-related stressors. The review of extant literature and the focus-group interview conducted among 20 college students led to the writing of items in the initial instrument grouped into eight themes. These were: (a) enrolment and admission-related stressors, (b) subject-related stressors, (c) teacher-related stressors, (d) classmate-related stressors, (e) schedule- 
related stressors, (f) classroom-related stressors, (g) financial-related stressors, and (h) expectation-related stressors.

The items in the initial instrument were further reviewed by 11 college students (Development Communication). After the review by the 11 college students, a trial-run using the initial instrument was conducted among 17 college students (15 Development Communication and two BS in Biology) The trial-run was done to check for the suitability of language used in the items, the ease of following the directions and the average length of time needed in answering the instrument. The minimal suggestions recorded during the trial-run served as bases for improvements done in the final instrument. The final instrument had 72 items to be responded by college students themselves using a four-point scale: one for "not at all stressful," two for "mildly stressful," three for "moderately stressful," and four for "severely stressful." These 72 items were specifically categorized under eight scales representing the identified components of academic stress: (1) enrolment and admission-related stressors with nine items, (2) subject-related stressors with 19 items, (3) teacher-related stressors with six items, (4) classmate-related stressors with five items, (5) schedule-related stressors with 10 items, (6) classroom-related stressors with 10 items, (7) financial-related stressors with three items, and (8) expectation-related stressors with 10 items.

Administration of the Survey Instrument: The survey instrument was administered to 1,210 college students who were chosen via systematic random sampling. The administration of the instrument was done during the Second Semester of School Year 2010-211.

Respondents of the Study: There were 1,210 respondents in this study. All of which were officially enrolled in a state college in the Philippines. Out of the 1,210 respondents, 481 were males which accounted for $39.75 \%$ of the total number of respondents while there were 729 females which accounted for $60.25 \%$ of the total number of respondents. The mean age of the respondents was 18.33 with a standard deviation of 2.12. The 1,210 respondents came from the following programs: Bachelor of Arts in English $(\mathrm{N}=55)$, Bachelor of Science in Agricultural Engineering ( $N=49)$, Bachelor of Science in Agricultural Business $(\mathrm{N}=32)$, Bachelor of Science in Agricultural Economics ( $N=6$ ), Bachelor of Elementary Education ( $\mathrm{N}=95)$, Bachelor of Science in Entrepreneurship ( $\mathrm{N}=12)$, Bachelor of Secondary Education ( $\mathrm{N}=194)$, Bachelor of Science in Biology ( $\mathrm{N}=37)$, Bachelor of Science in Development Communication ( $\mathrm{N}=24)$, Bachelor of Science in Agricultural Forestry $(\mathrm{N}=4)$, Bachelor of Science in Mathematics $(\mathrm{N}=32)$, Bachelor of Science in Agriculture ( $=164)$, Bachelor of Science in Home Economics ( $\mathrm{N}=10)$, Bachelor of Science in Hotel and Restaurant Management $(\mathrm{N}=159)$, Bachelor of Science in Home Technology ( $N=92)$, Diploma in Computer Programming $(\mathrm{N}=52)$, and Doctor of Veterinary Medicine $(\mathrm{N}=29)$.

Based on the tally, $16.03 \%$ of the respondents came from Bachelor of Secondary Education, followed by 13.55\% from Bachelor of Science in Agriculture, 13.14\% from Bachelor of Science in Hotel and Restaurant Management, and 7.85\% from Bachelor of Elementary Education. These four programs accounted for more than half the respondents.

Statistical Analysis: To test the hypotheses of the study, independent samples t-test was used. The independent samples t-test is used when one wants to examine the mean difference between two exclusive or independent groups (Hyman \& Sierra, 2010). Independent samples t-test was performed using SPSS version 15.0.

\section{Results}

Table 1: Difference in the Perception of Enrolment and Admission-related Stressors

\begin{tabular}{lllllll}
\hline Gender & $\mathbf{N}$ & $\mathbf{M}$ & SD & T & Df & Sig. (2-tailed) \\
\hline Males & 481 & 22.92 & 5.53 & -1.25 & 1208 & 0.21 \\
Females & 729 & 22.55 & 4.78 & & & \\
\hline
\end{tabular}

Note. Equal Variances Assumed 
Table 1 presents the difference in the perception of enrolment and admission-related stressors between males and females. As seen in the Table, there is no significant difference between the male and female respondents. With reference to the mean scores, male respondents scored higher. It must be noted that the mean scores represents the mean of the total scores of the respondents in the enrolment and admissionrelated stressors' scale of the survey instrument. Since there are nine items in this scale, total scores can range from nine to 36. Stressors considered to be related with enrolment and admissions were: enrolling, getting of class cards, signing of clearances, settling of unpaid accounts, securing of examination permits, securing of class schedules, following of enrolment procedures, changing/adding of subjects, and validating of subjects.

Table 2: Difference in the Perception of Subject-related Stressors

\begin{tabular}{lllllll} 
Gender & $\mathbf{N}$ & $\mathbf{M}$ & $\mathbf{S D}$ & $\mathbf{T}$ & $\mathbf{D f}$ & Sig. (2-tailed) \\
Males & 481 & 45.93 & 11.21 & -1.99 & 1208 & 0.05 \\
Females & 729 & 44.73 & 9.66 & & & \\
\hline
\end{tabular}

Note. Equal Variances Assumed

Table 2 presents the difference in the perception of subject-related stressors between males and females. As seen in the Table, there is a significant difference between the male and female respondents. With reference to the mean scores, male respondents scored higher. It must be noted that the mean scores represents the mean of the total scores of the respondents in the subject-related stressors' scale of the survey instrument. Since there are 19 items in this scale, total scores can range from 19 to 76 . Stressors considered to be related with subjects were: passing written examinations, passing oral examinations, participating in classroom discussions, conducting researches, completing seat works, searching for reference materials, completing assignments, submitting requirements, beating requirements' deadlines, completing requirements, passing unannounced examinations, dealing with unannounced graded recitations, understanding classroom discussions, preparing for an examination, passing a removal examination, passing practical examination, writing of assignments, conducting laboratory experiments, and participating in extension activities.

Table 3: Difference in the Perception of Teacher-related Stressors

\begin{tabular}{lllllll}
\hline Gender & $\mathbf{N}$ & $\mathbf{M}$ & SD & t & Df & Sig. (2-tailed) \\
\hline Males & 481 & 13.91 & 4.03 & 2.07 & 1208 & 0.04 \\
Females & 729 & 14.38 & 3.78 & & & \\
\hline
\end{tabular}

Note. Equal Variances Assumed

Table 3 presents the difference in the perception of teacher-related stressors between males and females. As seen in the Table, there is a significant difference between the male and female respondents. With reference to the mean scores, female respondents scored higher. It must be noted that the mean scores represents the mean of the total scores of the respondents in the teacher-related stressors' scale of the survey instrument. Since there are six items in this scale, total scores can range from six to 24. Stressors considered to be related with teachers were: dealing with strict teachers, coping with teacher's teaching methodologies, adjusting to teachers' unfair treatment of students, dealing with teachers in general, adjusting with teachers' treatment of students, and attending to teachers' request.

Table 4: Difference in the Perception of Classmate-related Stressors

\begin{tabular}{lllllll}
\hline Gender & N & M & SD & T & Df & Sig. (2-tailed) \\
\hline Males & 481 & 10.55 & 3.48 & -0.22 & 1208 & 0.83 \\
Females & 729 & 10.51 & 3.24 & & & \\
\hline
\end{tabular}

Note. Equal Variances Assumed

Table 4 presents the difference in the perception of classmate-related stressors between males and females. As seen in the Table, there is no significant difference between the male and female respondents. However, with reference to the mean scores, male respondents scored higher. It must be noted that the mean scores represents the mean of the total scores of the respondents in the classmate-related stressors' scale of the survey instrument. Since there are five items in this scale, total scores can range from five to 20 . Stressors 
considered to be related with classmates were: arguing with classmates, disliking classmates, competing with classmates, bullying by classmates, and conducting activities with classmates.

Table 5: Difference in the Perception of Schedule-related Stressors

\begin{tabular}{lllllll}
\hline Gender & N & M & SD & T & Df & Sig. (2-tailed) \\
\hline Males & 481 & 23.18 & 6.69 & -2.51 & 1208 & 0.01 \\
Females & 729 & 22.28 & 5.76 & & & \\
\hline
\end{tabular}

Note. Equal Variances Assumed

Table 5 presents the difference in the perception of schedule-related stressors between males and females. As seen in the Table, there is a significant difference between the male and female respondents. With reference to the mean scores, male respondents scored higher. It must be noted that the mean scores represents the mean of the total scores of the respondents in the schedule-related stressors' scale of the survey instrument. Since there are 10 items in this scale, total scores can range from 10 to 40. Stressors considered to be related with schedules were: attending classes, attending make-up classes, making sense of too many vacant periods, managing too little vacant periods, moving from one classroom to the other, moving from one building to the other, commuting to and from the school, participating in extra-curricular activities, attending meetings of student organizations, and attending school programs.

Table 6: Difference in the Perception of Classroom-related Stressors

\begin{tabular}{lllllll}
\hline Gender & $\mathbf{N}$ & $\mathbf{M}$ & SD & $\mathbf{t}$ & Df & Sig. (2-tailed) \\
\hline Males & 481 & 25.70 & 7.10 & 5.84 & 1208 & 0.00 \\
Females & 729 & 28.05 & 6.66 & & & \\
\hline
\end{tabular}

Note. Equal Variances Assumed

Table 6 presents the difference in the perception of classroom-related stressors between males and females. As seen in the Table, there is a significant difference between the male and female respondents. With reference to the mean scores, female respondents scored higher. It must be noted that the mean scores represents the mean of the total scores of the respondents in the classroom-related stressors' scale of the survey instrument. Since there are 10 items in this scale, total scores can range from 10 to 40 . Stressors considered to be related with classrooms were: bearing with overcrowded classrooms, bearing with classrooms that have poor or no ventilation, bearing with classrooms that have poor or no lighting, bearing with dirty classrooms, bearing with noisy classrooms, looking for available classrooms, bearing with fowlsmelling classrooms, waiting for classrooms to be vacated, bearing with classrooms with limited seats, and bearing with distractions in or outside the classrooms.

Table 7: Difference in the Perception of Financial-related Stressors

\begin{tabular}{lllllll}
\hline Gender & N & M & SD & t & Df & Sig. (2-tailed) \\
\hline Males & 481 & 8.06 & 2.73 & 0.74 & 1208 & 0.46 \\
Females & 729 & 8.17 & 2.42 & & & \\
\hline
\end{tabular}

Note. Equal Variances Assumed

Table 7 presents the difference in the perception of financial-related stressors between males and females. As seen in the Table, there is no significant difference between the male and female respondents. However, with reference to the mean scores, female respondents scored higher. It must be noted that the mean scores represents the mean of the total scores of the respondents in the financial-related stressors' scale of the survey instrument. Since there are three items in this scale, total scores can range from three to 12 . Stressors considered to be related with finances were: budgeting of allowance, dealing with unexpected expenses, and saving money for projects.

Table 8: Difference in the Perception of Expectation-related Stressors

\begin{tabular}{lllllll}
\hline Gender & N & M & SD & t & Df & Sig. (2-tailed) \\
\hline Males & 481 & 24.07 & 6.88 & 2.90 & 1208 & 0.00 \\
Females & 729 & 25.23 & 6.72 & & & \\
\hline
\end{tabular}

Note. Equal Variances Assumed 
Table 8 presents the difference in the perception of expectation-related stressors between males and females. As seen in the Table, there is a significant difference between the male and female respondents. With reference to the mean scores, female respondents scored higher. It must be noted that the mean scores represents the mean of the total scores of the respondents in the expectation-related stressors' scale of the survey instrument. Since there are 10 items in this scale, total scores can range from 10 to 40. Stressors considered to be related with expectations were: thinking about getting a job after college, handling expectations of parents, handling expectations of relatives, handling expectations of siblings, handling expectations of friends, worrying about the future, handling expectations of teachers, handling expectations of benefactors, handling expectations of people in the community, and handling self-expectations.

Table 9: Difference in the Perception of Academic Stressors in General between Males and Females

\begin{tabular}{lllllll}
\hline Gender & N & M & SD & T & Df & Sig. (2-tailed) \\
\hline Males & 481 & 174.33 & 34.21 & 0.84 & 1208 & 0.40 \\
Females & 729 & 175.89 & 30.03 & & & \\
\hline
\end{tabular}

Note. Equal Variances Assumed

Table 9 presents the difference in the perception of academic stressors in general between males and females. As seen in the Table, there is no significant difference between the male and female respondents. However, with reference to the mean scores, female respondents scored higher. It must be noted that the mean scores represents the mean of the total scores of the respondents in the survey instrument as a whole. Since there are 72 items in the instrument, total scores can range from 72 to 288.

\section{Discussion}

A study on academic stress along gender lines is a worthy undertaking and the results of this study only showed that male and female respondents differed significantly in their perception of subject, teacher, schedule, classroom, and expectation-related stressors but did not significantly differ in their perception of enrolment and admission, classmate, and financial-related stressors which partly proved the first hypothesis of this study. However, no significant difference was found between the male and female respondents in their perception of academic stressors in general which disproved the second hypothesis of this study. Basing on the mean scores, male respondents scored higher on four out of the eight identified components of academic stress and these were on stressors related to enrolment and admissions, subjects, classmates, and schedules. On the other hand, female respondents scored higher also on four out of the eight identified components of academic stress and these were on stressors related to teachers, classrooms, finances, and expectations.

The results of this study proved that indeed there was strong evidence that the perception of academic-stress between males and females was very different. This claim was in relation to the significant differences found in five (subject, teacher, schedule, classroom, and expectation-related) out of the eight identified components of academic stress reflected in the survey instrument. The difference in the perception of stress between males and females had already been recognized by earlier studies conducted. For example, in the study conducted by Gentley et al. (2007), results suggest that significant gender differences exist in the experience of stress. These differences according to the researchers can be attributed to differences in perception although the study was conducted among adults living in Hawaii. Additionally, the claim that males and females differ in their perception of stress was proven in another study. Misra and Castillo (2004) found that perception of males and females regarding stress differed and the study was conducted among American and international students. The researchers suggest that "mental health practitioners may also consider using treatment interventions on the basis of these differences" (p. 146).

Regarding the non-significant differences in the perception of academic stress between males and females as reflected in academic stress in general and in three (enrolment and admission, classmate, and financialrelated) out of the eight identified components of academic stress in this study was parallel with the findings of Watson in 2002 who found no significant differences in the perceived stress between male and female students. However, the study was limited to students enrolled in Nursing and Social Work programs. Moreover, with female respondents scoring higher in their perception of academic stress in general was 
consistent with the finding of other studies earlier conducted. Eun-Jun (2009) found that females scored higher on the Perceived Stress Scale which was administered to international students. Similarly, Matud (2004) found that females scored significantly higher than males in chronic stress and minor daily stressors while Sulaiman et al. (2009) found that male students experienced less stress compared to the female students. Interestingly, Misra and Mckean (2000) found that positive association between anxiety and academic stress and trait anxiety being a significant predictor of academic stress. According to them, "individuals who scored high on trait anxiety experienced higher stressors and reactions to stressors. Females exhibited higher anxiety (both trait and state) than males" (p. 49).

In the end, it must be remembered that the investigation of academic stress is important. This importance is manifested by the fact that several studies have already documented the effects of stress on students (e.g. Agolla \& Ongori, 2009; Hussain et al., 2008; Kumar \& Jejurkar, 2005; Masih \& Gulrez, 2006; Shaikh et al., 2004; Sulaiman et al., 2009). Although, more studies must still be conducted on the subject matter to be able to thoroughly understand academic stress as it affects students so that better intervention programs be developed. Better intervention programs for college students are equated to better performances academically and sound well-beings personally.

\section{Conclusion and Recommendation}

Although, males and females did not significantly differ in their perception of academic stressors in general, female respondents still scored higher. This only shows that females were the more affected gender when it came to academic stress. This conclusion was consistent with the findings of other studies (e.g. Eun-Jun, 2009; Matud, 2004; Misra \& Mckean, 2000; Sulaiman et al., 2009). It was also interesting to highlight that significant differences in the perception of five (subject, teacher, schedule, classroom, and expectationrelated) out of the eight components of academic stress identified in the survey instrument used. These differences can be attributed to differences in perception (Gentley et al., 2007; Misra \& Castillo, 2004).

The higher mean scores among female respondents in general and the significant differences between the mean scores of male and female respondents in the five out of the eight identified components of academic stress merits due attention. These significant findings should be taken into consideration when planning intervention programs to college students that has something to do with academic stress. Also, similar studies are encouraged to be conducted in order to compare and contrast results to have a more thorough understanding of academic stress along gender lines.

Limitations of the Study: This study was limited to the use of a researcher-developed instrument in investigating academic stress among college students with emphasis on gender differences. The 1,210 respondents of this study came from one state college in the Philippines only. Therefore, the results of this study cannot be generalized in other schools whether inside or outside of the country.

\section{References}

Agolla, J. E. \& Ongori, H. (2009). An Assessment of Academic Stress among Undergraduate Students: The Case of University of Botswana. Educational Research and Review, 4(2), 63-70.

Ang, R. P. \& Huan, V. S. (2006). Relationship between Academic Stress and Suicidal Ideation: Testing for Depression as a Mediator using Multiple Regression. Child Psychiatry and Human Development, 37(2), 133-143.

Cheng, K. W. (2009). A Study of Stress Sources among College Students in Taiwan. Journal of Academic and Business Ethics, 2, 1-8.

Conner, J., Pope, D., \& Galloway, M. (2010). Success with Less Stress. Health and Learning, 67(4), 54-58.

Eun-Jun, B. (2009). The Effects of Gender, Academic Concerns, and Social Support on Stress for International Students, Unpublished PhD thesis, University of Missouri-Columbia. 
Gentry, L. A., Chung, J. J., Aung, N., Keller, S., Heinrich, K. M., \& Maddock, J. E. (2007). Gender Differences in Stress and Coping among Adults Living in Hawai i. Californian Journal of Health Promotion, 5(2), 89102.

Johnson, M. (2009). Community College Students' Perception of Stress. Journal of Biology of Exercise, 5(1), 1528.

Humphrey, J. H., Yow, D. A., \& Bowden, W. W. (2000). Stress in College Athletes: Causes, Consequences, Coping. Binghamton, NY: The Haworth Half-Court Press. An imprint of the Haworth Press, Inc.

Hussain, A., Kumar, A., \& Husain, A. (2008). Academic Stress and Adjustment among High School Students. Journal of the Indian Academy of Applied Psychology, 34(special issue), 70-73.

Hyman, M. R. \& Sierra, J. J. (2010). Marketing Research Kit for Dummies. Hoboken, NJ: Wiley Publishing Inc.

Jogaratnam, G. \& Buchanan, P. (2004). Balancing the Demands of School and Work: Stress and Employed Hospitality Students. International Journal of Contemporary Hospitality Management, 16(4), 237-245.

Kumar, S. \& Jejurkar, K. (2005). Study of Stress Level in Occupational Therapy Students during their Academic Curriculum. The Indian Journal of Occupational Therapy, 37 (1), 5-14.

Matud, M. P. (2004). Gender Differences in Stress and Coping Styles. Personality and Individual Differences, 37(7), 1401-1415

Masih, P. P. \& Gulrez, N. K. (2006). Age and Gender Differences on Stress. In Husain, A. \& Khan, M. I. (eds.). Recent Trends in Human Stress Management (97-104). New Delhi, India: Global Mission Publishing House.

Misra, R. \& Castillo, L. G. (2004). Academic Stress among College Students: Comparison of American and International Students. International Journal of Stress Management, 11 (2), 132-148

Misra, R. \& McKean, M. (2000). College Students' Academic Stress and its Relation to their Anxiety, Time Management, and Leisure Satisfaction. American Journal of Health Studies, 16(1), 41-51

Richlin-Klonsky, J. \& Hoe, R. (2003). Sources and Levels of Stress among UCLA Students. Student Affairs Briefing, 2.

Shah, M., Hasan, S., Malik, S., \& Sreeramareddy, C. T. (2010). Perceived Stress, Sources and Severity of Stress among Medical Undergraduates in a Pakistani Medical School. BMC Medical Education, 10(2), 1-8.

Shaikh, B. T., Kahloon, A., Kazmi, M., Khalid, H., Nawaz, K., Khan, K. A., \& Khan, S. (2004). Students, Stress and Coping Strategies: A case of Pakistani Medical School. Education for Health, 17(3), 346-353.

Sulaiman, T., Hassan, A., Sapian, V. M., \& Abdullah, S. K. (2009). The Level of Stress among Students in Urban and Rural Secondary Schools in Malaysia. European Journal of Social Sciences, 10(2), 179-184.

Watson, R. L. (2002). A Comparison of Perceived Stress Levels and Coping Styles of Junior and Senior Students in Nursing and Social Work programs, Unpublished PhD thesis, Marshall University.

Wilks, S. E. (2008). Resilience amid Academic Stress: The Moderating Impact of Social Support among Social Work Students. Advances in Social Work, 9(2), 106-125 